\title{
Daily Meetings Chaired by an Adolescent in a Psychiatric Ward*
}

\author{
By Peter Bruggen, Carol Dunne and Charles O'Brian, Hill End Hospital, Herts
}

The reason for admission was early developed as a focus of work in Hill End Adolescent Unit (Bruggen et al, 1973). Boys and girls (they were all under 16) were admitted on the authority of those in parental charge, and the reason usually was that their parents needed a break from the anxiety of having them at home, or that their children's homes could no longer cope with them and that their social workers had nowhere else to place them.

Useful as such a focus was in limiting denial and encouraging work, it could hardly be the main focus for everything all the time. It was not for the community meetings. These floundered. It was only after four years that a similar search for a reason was applied and a focus and function was found for them.

Why had we had 'community meetings' in the first place? They were certainly fashionable and all 'progressive' institutions had them. It seemed, a priori, a good idea for us all to meet. It helped staff (perhaps particularly the consultant) not to feel too isolated. Nevertheless, the lack of definition of function, or of much literature at all on the subject (for exceptions, see Rappoport, 1960; Edelson, 1964; Wax, 1965; Daniels and Rubin, 1969; Schiff and Glassman 1969; and Springman, 1970), suggested a ritualized institutionism such as might be attributed also to the ward round, case conference or morning assembly. Furthermore, the very words 'community meeting' suggested an idealized denial of difierences of role between patients and staff.

\section{Development}

The handover and the conductor

After we, in the staff group, had opened up our communications, had decided not to talk about colleagues in their absence, nor to have secrets about work, it seemed unnecessary for there to be a private handover between morning and afternoon shifts of nurses in the office. And yet, that handover was, for reasons of professional responsibility and common sense management, necessary. We brought that handover into the community meeting, giving it a function, which was understandable to all concerned. Also, each person in the meeting had a role-to speak or to hear what was said about what had happened.

The morning charge nurse summarized events of the previous 24 hours, commented on the mood of the group and gave any other information which seemed relevant to him. The meetings were less of an agony, and some purpose appeared in them.

Soon, with enthusiasm for facilitating structure, the staff

"Based on a paper read at the VII International Congress of Group Psychotherapy, Copenhagen 1980. introduced a new role, that of conductor. Another member of staff, often a social worker, took that on.

Yet, despite those changes and the Unit's professed interest in integrating authority and caring, it was difficult for staff members not to appear negative or punitive.

Relief came from an unexpected, but obvious source. Something else followed after the staff had opened up their communications. More ideas came from those they were looking after. One of the boys and girls suggested that they themselves should give the handover. Staff discussed this in meetings and expressed many anxieties. The adolescents might be too punitive. The staff had to protect them from their own sadism. Adolescents could not be objectiv. enough. They would use the role to manipulate each other, disrupt the work or 'split' the staff.

When they were allowed to take over this role, the boys and girls were, of course, more fluent, more flexible, more imaginative and less punitive than we, the staff, had ever managed to be.

The next suggestion also came from the boys and girls. It was that they should take over the role of chairperson, or conductor, for the meeting. Again, their handling of this piece of delegated authority was far more creative than the staff had ever achieved. Peer support and peer sanction were more sensitive, serious and effective.

With these two changes, the community meeting became comfortably institutionalized. Boys and girls would sit patiently waiting for the meeting to start when staff arrived. Staff were rarely lato-boys and girls very, very rarely.

As the information shared became more meaningful, ideas and suggestions for future work or focus could arise spontaneously.

\section{Other functions}

Greeting new people, decision making, an institutional saying farewell, and offering an opportunity to monitor staff, were introduced later.

\section{The practice}

\section{Boundaries}

The meeting takes place in the first public room of the Unit. In the morning 'work meeting' one of the boys or girls will have volunteered to arrange it.

Chairs, all of the same height and build, are placed in a circle. The meeting starts at 1.15 and finishes at $2.00 \mathrm{pm}$, and is not interrupted (staff may be allowed by the conductor to come in late within the first 2 or 3 minutes but no later).

\section{Structure}

(a) Announcements: The conductor states the time and calls for any announcements. 
Social Worker: 'Mr. Bardon (student) sends his apologies for this meeting.'

Charge Nurse: 'I'll be away on holiday next week so my last shift will be on Saturday afternoon and I won't be in again until the following Monday.'

Boy: 'I've got a review meeting this afternoon.'

Girl: 'The decision about excluding me from school has to be reviewed.'

The inspection, done weekly by two members of staff and two of the boys and girls, is read out on Wednesdays.

The conductor makes a brief statement about the state of the group ('The group have been a bit high, but quite supportive today' or 'The group have been a bit split today'), and of the state of the staff ('The staff have been very nice to have around and have been supportive today' or 'The staff have been very tired' or 'Staff have been helpful and supportive but $\mathrm{Mr}$ Brown has been in a bad temper this morning').

(b) Handover: The conductor has allocated to each member the same number of minutes. He says 'Carry on' and the other member of the group, who also volunteered in the work meeting, begins. Sometimes the handover is a repetitive formula, heavily loaded with the jargon which has evolved over the years ('You worked in the Action Group. You were nice to be with'). Sometimes it is factual and informative ('You were very upset last night after you had a phone call with you mum') and sometimes it is forcefully perceptive ('You were upset last night, but I think that you were trying to get attention').

For the remainder of the turn, some sort of dialogue between the boy or girl and the rest of the meeting takes place. They may be invited to elaborate on work they have done in the action group or to report back from their review meeting. They may do this with little encouragement; they may accept the offer from somebody else to do it for them.

Sometimes there is heavy confrontation from another boy or girl ('You are always provoking us' or 'You've got to face it, you are getting chronic!'), or from staff, ('You've got to accept that we won't tolerate that sort of behaviour here').

Sometimes strong support is offered, in words, or by neighbours putting an arm around them.

In anticipation of a meeting with parents, a boy or girl may be invited to 'Speak to them now. If he was here, what would you say to him?' and to repeat the words they say.

At the end of each person's turn, the conductor says 'Carry on'.

(c) Decisions: At the end of the handover time, the conductor asks for any decisions which are to be reviewed. Sometimes it is very straightforward, as when the school staff have excluded somebody because they could not tolerate his disruptiveness, and that person has done a great deal of work by sobbing and talking about feelings which were disturbing him. Sometimes a sullen and resentful attitude has been fairly consistent during the community meeting, and staff members say that they feel 'just as anxious as before'. In such a case, the stafi may then add, 'But can you help me?' Here, sometimes, the adolescent may say, 'I'1 be alright' or, 'I'll work now', and this enables staff to feel easier and to say 'Well, then, I'd like to have you back.'

The emphasis is on the decision which is being reviewed and not on the adolescent. And the decision is based on the anxiety level of staff.

The supremacy of the meeting and of the conductor

The staff who are in charge of the Unit have delegated their authority to the conductor to run this meeting. The structure is one which must be used by all concerned. If a staff member feels that one of the boys or girls is disrupting the work, he must address himself to the conductor:

'Excuse me, David (conductor), will you ask lan to take the meeting more seriously and not to keep staring round at Jackie while the handover is being done.'

'David, I am finding it difficult to concentrate because of the noise Jenny is making sitting next to me. Please will you ask her to stop.'

Occasionally, it is suggested that people should change places. If things become more dificult, staff again address themselves to the conductor, saying, 'How can we support you to conduct this meeting?'

We believe that, however distressed or crazy one may be feeling, one's feelings can be shared with others, (while adolescents are expected to share their crazy feelings with the meeting, staff are expected to hold theirs until the staff meeting).

Nobody is allowed to leave this meeting. The degree of restraint is not limitless, but both adolescents and staff have made considerable efforts to hold somebody from leaving the room. If they fail or if someone does rush out, then, with the agreement of the conductor, one or two members of staff may go to try to persuade him back. Again, the decision for staff to do this, through the conductor, should be dictated by their experience of their anxiety.

Occasionally, boys or girls have asked to leave because they have felt sick. This is not accepted. Vomiting is also seen as something to be faced and tolerated. A bowl will be provided (but has only been used on one occasion).

\section{The new therapies}

One of the biggest changes which has occured in the tone of the community meeting has come with the introduction of body work, and other aspects of newer therapies, into daily practice.

Participants who in their turn appear distressed but have arms or legs crossed will be encouraged to uncross their arms and put their feet on the floor.

Anyone who talks of a difficulty in trusting will be encouraged to look around the group, identify the people not trusted and say 'I don't trust you'.

'Say it as if you mean it' may be said to someone who makes a statement such as 'I am angry', 'I am going to work'. Controlled shouting may be encouraged. 
If someone is obviously thoughtful or distressed, but not sharing the experience, and if the two people on either side have not already put a hand or an arm around his shoulders, the conductor may say 'Support him'.

As with all the work in the Unit, ' $I$ ' statements are expected, and the handover is directed to the person who is the subject at each turn. ('You worked in the Action Group and you were very upset afterwards.' 'You called an extra meeting just after handover to the night staff.')

\section{The leaving exercise}

The night nursing staff and adolescent group evolved a leaving exercise which is now incorporated into the community meeting, by starting it a quarter of an hour early.

At the end of the usual meeting, the conductor asks everybody to stand. The leaver goes around the room, pausing to face each staff member and adolescent in turn. The pair put arms on each other's shoulders and each says to the other whatever it is, which, if not said, will be carried with them. Remarks made by both sides have included.

'I hardly know you, but I wish you well.'

'I'm very pleased not be seeing you any more because I've not seen you doing any work here and you've stopped me getting on.'

'It's been so tiring working with you because you've been so destructive but I still do wish you well.'

'At first I didn't like you but then I found you helpful and supportive and I'll miss you a lot.'

'I've seen you face some difficult and painful things while you've been here and do a great deal of work which I respect you for. I know you have the strength to face all the problems that you are going to have, and I wish you well.'

'I've found you supportive, but I wish you'd do some work on yourself or you'll stay here for ages.'

These exercises are often extremely emotional and tearful for adolescents and staff. At the end, the conductor asks everybody to sit down and hold hands for a few moments before closing the meeting.

\section{Staff differences, support and visitors}

Bringing into it the formal handover from morning to afternoon nurses, having present the psychiatrists, social workers, nursing officer and teachers, make the community meeting the main decision-making moment of the day. Bringing together staff should render it less likely that groups will be split from each other and should enable difierences of opinion to be aired and discussed in public. It should also make more possible the tempering of the view of a staff member who is feeling tired with that of a more vigorous and more detached colleague:

'Well, I've been off for four days and feel quite fresh, so I'm prepared to have you back with the group.'

Staff do not need to support each other automatically and should be prepared to offer differing points of view. Again fresher, or more detached staff have an important role. They can detect and expose when colleagues give in to the tempta- tion to lecture rather than express anxiety or make a decision.

'I don't think we should just go on lecturing you. Can you say anything that will make it easier for the school staff to feel prepared to try again?'

The introduction of formal comments on staff (a staff suggestion) was to deal with anxiety about festering grievances. It also provides reassurance to the adolescents by enabling them to see criticisms accepted and to see that staff differences or disagreements need not be disasters. It offers the learning experience of negotiation.

The community meeting has been, by its very publicness, a convenient means of sharing work with visitors. Apart from responding to the conductor's request for them to introduce themselves, their role is a passive one and they do not stand during a leaving exercise. Their reactions have been varied from feeling privileged, overwhelmed, tearful, incredulous, horrified or affronted. They have been particularly displeased with the sharp cut-off after each handover (a feature of this meeting only).

Staff have found it useful to remove some of the mystery about work, and comments made later by visitors have been helpful.

\section{Conclusion}

This community meeting is a formalized and a ritualized checking point to review where each is in the work being done. It is an opportunity for understanding emotional work. It may be helpful in planning what work to do in the other groups. It is an opportunity for making decisions on patient management in an open way. It may be only a taking note of working, living and being together.

None of these secondary things occurred in any meaningful way until redefinition of the primary function of the meeting and the primary role of the participants. The meeting is to provide a container for the handover, and the participants are there to give or receive it.

\section{REFERENCES}

Brugoen, P., Byng-Hall J., \& Prtt-Aikens, T. (1973) The reason for admission as a focus of work for an adolescent unit. British Journal of Psychiatry, 122, 568, 319-329.

Edelson, M. (1964) Ego Psychology, Group Dynamics and the Therapeutic Community. New York: Grune and Stratton.

DANiELS, D., \& RUBN, R. (1968) The community meeting: an analytic study and a theoretical statement. Archives of General Psychiatry, 18, 60-75.

RAPPOPORT, R. N. (1960) Community as Doctor. London: Tavistock.

SCHIFF, S. B. \& Glassman, S. M. (1969) Large and small group theory in a state mental health center. International Journal of Group Psychotherapy, 19, 150-57.

SPRINGMAN, R. (1970) A large group. International Journal of Group Psychotherapy, 20, 210-18.

WAX J. (1965) Analyzing a therapeutic community meeting. International Journal of Group Psychotherapy, 15, 29-36. 